\title{
PEMODELAN NUMERIK DATA POTENSIAL DIRI (SELF POTENTIAL)
}

\author{
Bayu Tambak Samudra danDwa Desa Warnana \\ Jurusan Teknik Geofisika, Fakultas Teknik Sipil dan Perencanaan, Instittut Teknologi Sepuluh Nopember \\ bayutsamudra@gmail.com
}

\begin{abstract}
Abstrak. Masalah kuantitatif dalam metode potensial diri terkadang masih ditemukan. Beberapa asumsi dan metode inversi digunakan dalam proses pembuatan modelnya agar dicapai error yang sekecil mungkin sehingga makin mendekati kondisi sebenarnya. Telah dilakukan "Pemodelan Numerik Data Potensial Diri (Self Potential)" untuk menginterpretasi secara kuantitatif anomali dan parameter geometri dari anomalinya. Asumsi model yang digunakan adalah geometri sederhana dari data potensial diri. Program untuk pemodelan numerik ini dibuat di perangkat lunak MATLAB yang meliputi pemodelan kedepan dan pemodelan kebelakang. Metode inversi yang dipakai yaitu metode yang dikembangkan oleh El-Araby (2003). Program yang dibuat selanjutnya diuji pada data sintetik (3 data) dan data sekunder (3 data). Berdasarkan hasil penelitian yang sudah dilakukan, untuk data sintetik, hasil RMS error-nya sebagian besar dibawah $10 \%$. Di samping itu, untuk data sekunder, hasilnya sesuai dengan referensi yang dipakai, dimana data sekunder 1 dan 2 saling memvalidasi karena berada pada daerah yang sama namun beda

lintasan pengukuran yang jenis sumber anomalinya adalah bola karena berkaitan dengan mineral tembaga. Sedangkan untuk data sekunder 3, sumber anomalinya adalah vertical cylinder, yaitu rembesan yang berhubungan dengan potensial streaming yang terjadi di daerah bendungan.
\end{abstract}

Kata Kunci: Anomali, Data, Model, Potensial Diri

\begin{abstract}
Quantitative problems in self-potential method sometimes still be found. Some of the assumptions and methods used in the model inversion in order to get the smallest possible error so perilously close to actual conditions. It has been done "Numerical Modeling of Self Potential Data" to quantitatively interpret anomalies and geometry parameters of the anomaly. Assumptions model that are used is the simple geometry of the self potential data. Program for numerical modeling is created in the MATLAB software that includes forward modeling and inverse modeling. The inversion method that is used is the method developed by El-Araby (2003). The program that created subsequently tested on synthetic data (3 data) and secondary data (3 data). Based on the research that has been done, for synthetic data, the results of all RMS error mostly is below 10\%. In addition, secondary data, the results are in accordance with the reference that was used, in which secondary data 1 and secondary data 2 validating each other because they are in the same area but different line measurement that type of source anomaly was associated with the sphere for a copper mineral. As for the secondary data 3, the source of the anomaly was a vertical cylinder, that is seepage associated with streaming potential that occurs in the area of the dam.
\end{abstract}

Keywords: Anomaly, Data, Model, Self Potential

\section{PENDAHULUAN}

Potensial diri (SP), atau yang biasa disebut potensial spontan merupakan pengukuran pasif dari potensial listrik yang dihasilkan melalui kopeling dengan beberapa mekanisme gaya lain; seperti hidrolik, kimia, atau termal. Secara konseptual, SP adalah teknik yang sangat sederhana dan serbaguna karena sinyal listrik yang ada di dalam media penghantar listrik (seperti bumi) dapat dideteksi dari jarak yang jauh dari lokasi mekanisme gaya. (Minsley, 1997)
Potensial diri juga merupakan beda potensial alami yang memiliki kegunaan untuk mencari tubuh mineral. Metode yang dikembangkan oleh El-Araby (2003) dapat menangani kesalahan acak dan data pengganggu lebih efektif daripada yang lain. Sebuah pendekatan least square minimization diimplementasikan untuk menentukan faktor bentuk (shape factor) menggunakan data pada semua titik dalam anomali potensial diri. Masalah selanjutnya berubah menjadi memecahkan persamaan linier pada faktor bentuk anomali untuk 
menghitung parameter lain seperti kedalaman, sudut polarisasi, dan shape factor.

Permasalahan lainnya adalah jarang ditemukan interpretasi kualitatif untuk metode SP, karena yang umum dilakukan adalah interpretasi kuantitatif, untuk itu diperlukan pemodelan numerik. Ada dua teknik pemodelan yang umum digunakan yaitu pemodelan kedepan (forward modeling) dan pemodelan kebelakang (inverse modeling). Dari permasalahan diatas, pada kasus ini diambil salah satu metode geofisika untuk

\section{TINJAUAN PUSTAKA}

\section{Konsep Self Potential (SP)}

Self potential (SP) atau disebut juga potensial diri adalah perbedaan potensial yang terjadi secara alami antara titik-titik di permukaan tanah. Perbedaan potensial dihasilkan di dalam bumi atau di dalam batuan yang teralterasi oleh kegiatan manusia maupun alam. Potensial alami terjadi akibat ketidaksamaan atau perbedaan materialmaterial, dekat larutan elektrolit dengan perbedaan konsentrasi dan karena aliran fluida di bawah permukaan. Selain itu, hal lain yang mengakibatkan terjadinya potensial diri di bawah permukaan yaitu dapat dihasilkan oleh perbedaan mineralisasi, aktivitas elektrokimia, aktivitas geothermal dan bioelektrik oleh tumbuh-tumbuhan (vegetasi) yang dipetakan untuk mengetahui informasi di bawah permukaan.

Penjelasan cukup lengkap untuk potensi mineralisasi dikemukakan oleh Sato dan Mooney (1960). Postulat dua reaksi setengah-sel elektrokimia dengan tanda berlawanan, satu katodik di atas permukaan air, anodik lainnya di kedalaman. Di katoda setengah-sel ada pengurangan zat dalam larutan dan mendapat elektron sedangkan di sel anoda reaksi oksidasi berlangsung dan melepas elektron. Fungsi zona mineral itu sendiri hanya untuk membawa elektron dari anoda ke katoda. Besarnya efek SP keseluruhan ditentukan oleh perbedaan potensial oksidasi antara larutan pada dua setengah-sel. Mekanisme ini diilustrasikan pada Gambar 1, yang menunjukkan aliran elektron dan ion yang meninggalkan permukaan atas bermuatan negatif, sedangkan yang lebih rendah bermuatan positif. (Telford, 1990) dimodelkan dengan pemodelan kedepan dan pemodelan kebelakang yaitu metode potensial diri (SP). Tujuannya untuk mengetahui seberapa besar kesesuaian antara model yang dibuat dengan model sebenarnya. Dalam hal ini, pada pemodelan kedepan, model telah ditentukan terlebih dahulu, kemudian dilakukan pemodelan kebelakang yang bertujuan untuk merekonstruksi model struktur bawah permukaan dari data observasi yang melibatkan teknik penyelesaian matematika dan statistik tertentu.

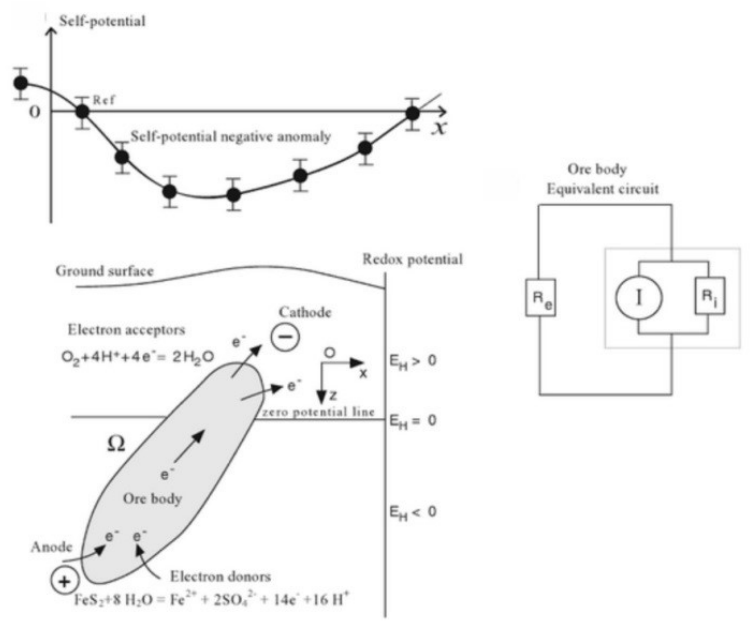

Gambar 1. Sketsa model geobattery klasik dari Sato dan Money untuk tubuh bijih dan persamaannya dengan sirkuit linear (Revil, 2013)

\section{Metode Self Potential (SP)}

Metode SP merupakan metode geofisika yang bersifat pasif, beda potensial alami yang dihasilkan oleh suatu material pada daerah survei diukur diantara dua titik elektroda di permukaan tanah. Nilai beda potensial yang terukur mulai dari beberapa milivolt hingga lebih dari satu volt. Tanda positif dan negatif yang terdapat pada nilai beda potensial adalah faktor yang penting untuk interpretasi anomali SP. (Tambunan, 1990)

\section{Pemodelan Kedepan untuk Metode Self Potential}

Pemodelan ke depan (forward modeling) merupakan proses perhitungan data yang secara teoritis akan teramati di permukaan bumi. Apabila diketahui parameter model bawah permukaan tertentu maka melalui proses pemodelan ke depan dapat dihitung data yang secara teoritik akan 
teramati di permukaan bumi. Jika respon suatu model cocok/sesuai dengan data, maka model yang digunakan untuk memperoleh respon tersebut dapat dianggap mewakili kondisi bawah permukaan di lokasi pengukuran. (Makhrani, 2013)

Anomali SP pada umumnya dihasilkan dari struktur yang paling terpolarisasi sepanjang profil utama diatas tubuh anomali yang diberikan oleh persamaan (1) pada titik $P(x i, z)$ (Gambar 2). (Yungul, 1950; Bhattacharya dan Roy 1981; Satyanarayana Murty dan Haricharen, 1985; Abdelrahman et al., 1997):

$V\left(x_{i}, z, \theta, q\right)=k \frac{x_{i} \cos \theta+z \sin \theta}{\left(x_{i}^{2}+z^{2}\right)^{q}}(1)$ untuk $(2 N+1)$ titik, $x \_i,(i=-N, \ldots,-1,0,1, \ldots, N)$.

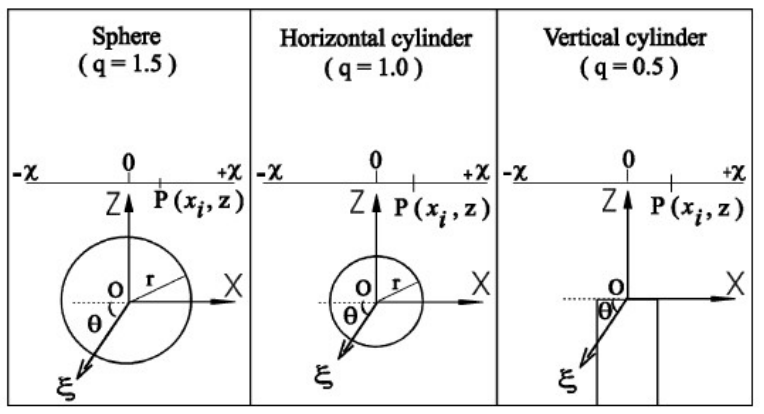

Gambar 2. Tampilan penampang untuk anomali SP sphere, horizontal cylinder, dan vertical cylinder (EIAraby, 2003)

\section{Pemodelan Kebelakang untuk Metode Self Potential}

Teori inversi didefinisikan sebagai suatu kesatuan teknik atau metode matematika dan statistika yang bertujuan untuk memperoleh informasi parameter model yang berguna dalam suatu sistem fisika yang pada hal ini fenomena yang ditinjau yaitu berdasarkan observasi terhadap sistem.

Inversi pada kasus ini menggunakan metode least square. Metode least square diperlukan untuk melakukan analisa apakah terdapat hubungan di antara dua variabel yang ditinjau, seberapa kuat hubungan yang terjadi.

Perbandingan antara ketiga anomali yang dihitung didasarkan pada parameternya melaui root mean square error (RMS). RMS ini mengukur seberapa sesuai respon model yang dihitung dengan data hasil pengukuran. RMS juga memiliki satuan yang sama dengan anomali SP. Nilai yang terendah dipilih untuk menunjukkan parameter hasil perhitungan yang dapat dipercaya.

$$
R M S=\sqrt{\frac{\sum_{i=1}^{N}\left[Y\left(x_{i}\right)-V\left(x_{1}, z, \theta, q\right)\right]^{2}}{2 N+1}}
$$

Dimana $\mathrm{Y}(\mathrm{xi})$ adalah nilai anomali SP hasil pengukuran sedangkan $\mathrm{V}$ adalah nilai anomali SP hasil perhitungan. (Hazra, 2010)

\section{METODOLOGI}

Metodologi yang digunakan dalam penelitian ini adalah: (1) pembuatan program dan pengujian untuk tahap pemodelan kedepan (forward modeling) dengan data sintetik; (2) pembuatan program dan pengujian untuk tahap pemodelan kebelakang (inverse modeling) dengan data sintetik; dan (3) evaluasi program yang dibuat dengan data sekunder.

\section{HASIL DAN PEMBAHASAN}

\section{Analisis dan Pembahasan Data Sintetik}

Program MATLAB yang dibuat, perlu dilakukan pengujian untuk melihat kemampuannya dalam memecahkan permasalahan interpretasional. Langkah pertama adalah mengaplikasikannya pada data sintetik, dengan tiga sumber anomali: model sumber spherical, model sumber horizontal cylinder, dan model sumber vertical cylinder menggunakan persamaan (1) untuk parameter model yang berbeda.

Anomali potensial diri untuk ketiga bentuk sumber telah dihitung untuk parameter berikut: sudut polarisasi $(\theta)=30$ derajat, momen dipol listrik $(k)=-100$ pada kedalaman yang berbeda $(z=2,2.5$, 3, 3.5, 4, 4.5, dan 5 unit). Hasilnya dapat dilihat pada (Gambar 3), (Gambar 4), dan (Gambar 5). 


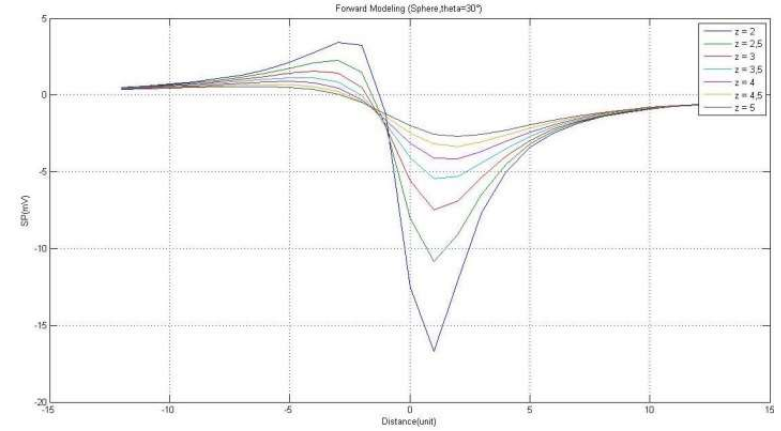

Gambar 3. Data sintetik untuk sumber spherical pada kedalaman yang berbeda

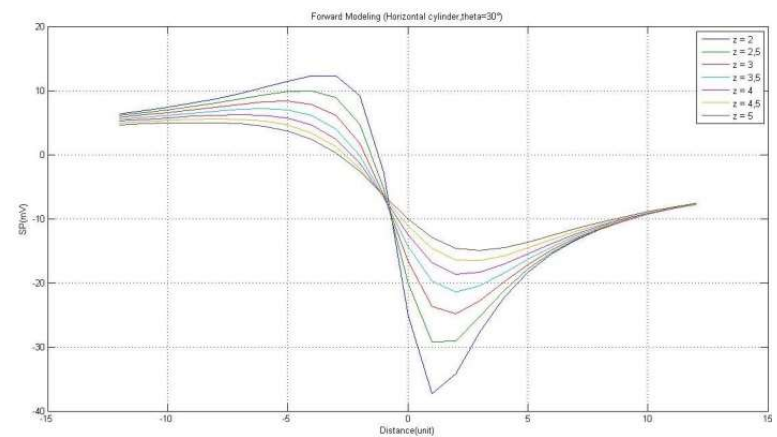

Gambar 4. Data sintetik untuk sumber horizontal cylinder pada kedalaman yang berbeda

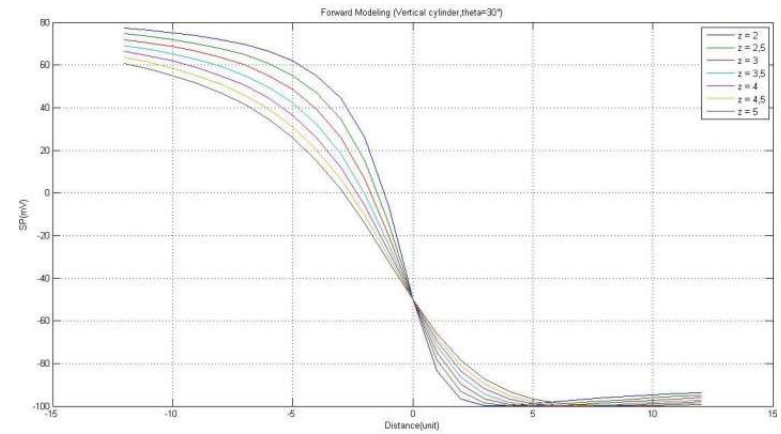

Gambar 5. Data sintetik untuk sumber vertical cylinder pada kedalaman yang berbeda

Setelah itu, anomali tadi digunakan sebagai input untuk program yang dibuatyang selanjutnya dilihat kesesuaian parameter modelnya melalui proses inversi. Nilai dari beberapa parameter yang didapat (q, $\theta, z, k$ ) kemudian digunakan untuk mendapatkan nilai SP baru melalui proses forward modeling. Nilai SP baru (hasil perhitungan) dan nilai SP awal dihitung nilai RMS error-nya menggunaan persamaan (2) untuk melihat kesesuaiannya. Semakin kecil nilainya maka semakin bagus hasil inversinya untuk mewakili kondisi awal pada ketiga model sumber anomali yang dipakai, hasilnya dapat dilihat pada Tabel 1.
Tabel 1. Perbandingan RMS error nilai SP untuk data sintetik

\begin{tabular}{|c|c|c|c|}
\hline \multirow{2}{*}{ Kedalaman } & \multicolumn{3}{|c|}{ RMS error } \\
\cline { 2 - 4 } & Sphere & $\begin{array}{c}\text { Horizontal } \\
\text { Cylinder }\end{array}$ & $\begin{array}{c}\text { Vertical } \\
\text { Cylinder }\end{array}$ \\
\hline 2.0 & 0.329 & 2.128 & 10.605 \\
\hline 2.5 & 0.127 & 1.060 & 7.791 \\
\hline 3.0 & 0.030 & 0.502 & 4.293 \\
\hline 3.5 & 0.036 & 0.169 & 3.168 \\
\hline 4.0 & 0.040 & 0.057 & 2.073 \\
\hline 4.5 & 0.018 & 0.103 & 1.364 \\
\hline 5.0 & 0.005 & 0.016 & 0.922 \\
\hline
\end{tabular}

Pada ketiga sumber anomali yang digunakan, mayoritas RMS error-nya dibawah $10 \%$, hal ini dapat diakibatkan dari pemilihan nilai $s$ ataupun dari proses pemodelan kedepan bagian kedua, yaitu yang dilakukan setelah hasil parameter anomalinya didapat dari proses pemodelan kedepan bagian pertama.

\section{Analisis dan Pembahasan Data Sekunder}

Data sekunder yang digunakan pada penelitian ini adalah data anomali SP di daerah tambang tembaga di Ergani, Turki (Weiss anomaly) dan data anomali SP di daerah tanggul bendungan di British Columbia, Kanada yang digunakan untuk penilaian kondisi rembesan (seepage).Pada daerah tambang tembaga dipakai dua lintasan pengukuran (Gambar 6).

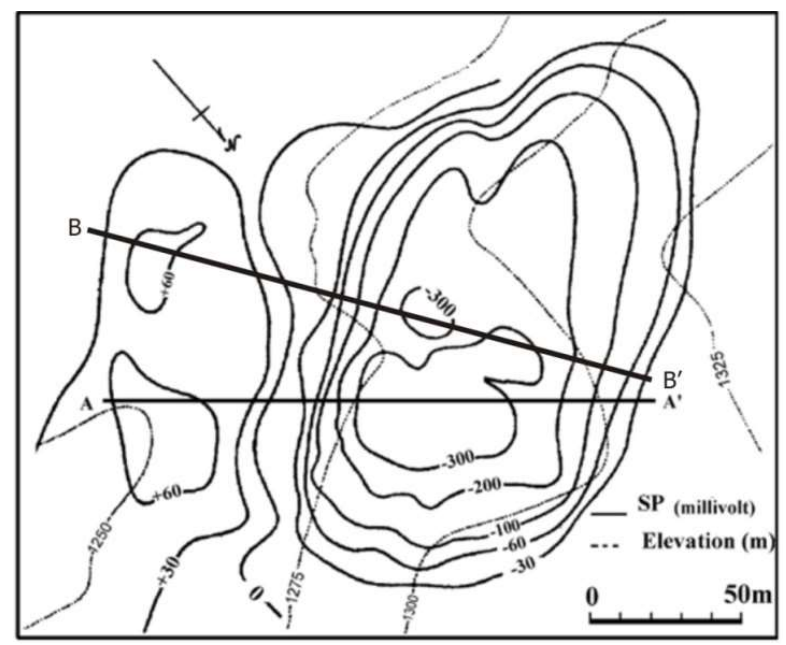

Gambar 6. Anomali Weiss, Ergani, Turki (Yüngül, 1950)

Program MATLAB yang telah dibuat selanjutnya diaplikasikan pada data sekunder di 
daerah tambang tembaga di Ergani, Turki (Weiss anomaly) untuk mendapatkan parameterparameternya. Profil anomali pada data sekunder 1 dan 2 ini didijitasi sebanyak 25 titik dengan interval $7.7 \mathrm{~m}$ (lintasan $\mathrm{A}-\mathrm{A}^{\prime}$ ) dan $8 \mathrm{~m}$ (lintasan B-B'). Nilai parameter yang didapatkan dilakakukan juga perbandingan dengan beberapa metode yang sudah dilakukan untuk kasus ini (Tabel 2).

Tabel 2. Perbandingan parameter model dari anomali Weiss

\begin{tabular}{|l|c|c|c|}
\hline Nama metode & Kedalaman & $\begin{array}{c}\text { Sudut } \\
\text { polarisasi }\end{array}$ & $\begin{array}{c}\text { Shape } \\
\text { factor }\end{array}$ \\
\hline Yüngül (1950) & $53.8 \mathrm{~m}$ & $40^{\circ}$ & 1.5 \\
\hline $\begin{array}{l}\text { Bhattacharya \& } \\
\text { Roy (1981) }\end{array}$ & $54 \mathrm{~m}$ & $30^{\circ}$ & 1.5 \\
\hline $\begin{array}{l}\text { Abdelrahman } \\
\text { (1996) }\end{array}$ & $52.9 \mathrm{~m}$ & $35.3^{\circ}$ & 1.5 \\
\hline Hazra (2010) & $45.7 \mathrm{~m}$ & $34.2^{\circ}$ & 1.67 \\
\hline $\begin{array}{l}\text { present } \\
\text { method - } \\
\text { (lintasan A-A') }\end{array}$ & $48.9 \mathrm{~m}$ & $35.85^{\circ}$ & 1.54 \\
\hline $\begin{array}{l}\text { present } \\
\text { method - } \\
\text { (lintasan B-B') }\end{array}$ & $76.4 \mathrm{~m}$ & $28.31^{\circ}$ & 1.50 \\
\hline
\end{tabular}

Perbedaan yang cukup besar ada di variabel kedalaman meskipun nilai shape factor-nya sudah sesuai dengan metode yang lain, hal ini dapat diakibatkan dari adanya dua anomali pada daerah tambang tersebut.

Sebelum menentukan nilai shape factor untuk dibandingkan pada tabel diatas, proses inversi dilakukan dengan melakukan pendekatan untuk ketiga bentuk sumber anomali (sphere, horizontal cylinder, dan vertical cylinder) dan perhitungan nilai RMS error. Hasil dari proses inversinya menunjukkan bahwa model sphere yang paling mendekati kondisi sekunder (sebenarnya) karena memiliki nilai RMS error terkecil (Tabel 3).

Tabel 3. Perbandingan RMS error untuk tiga bentuk anomali pada data sekunder 1 (lintasan A-A') dan data sekunder 2 (lintasan B-B')

\begin{tabular}{|c|c|c|}
\hline Lintasan & Shape body & RMS error \\
\hline \multirow{4}{*}{ A-A' } & Sphere & 37.97 \\
\cline { 2 - 3 } & $\begin{array}{c}\text { Horizontal } \\
\text { cylinder }\end{array}$ & 45.51 \\
\cline { 2 - 3 } & Vertical cylinder & 78.99 \\
\hline \multirow{2}{*}{ B-B' $^{\prime}$} & Sphere & 40.49 \\
\cline { 2 - 3 } & Horizontal & 44.33 \\
\hline
\end{tabular}

\begin{tabular}{|c|c|c|}
\hline & cylinder & \\
\cline { 2 - 3 } & Vertical cylinder & 50.01 \\
\hline
\end{tabular}

Hasil tersebut juga sesuai dengan Yüngül (1950) yang menyatakan bahwa anomali Weiss ini memiliki bentuk bola (sphere).

Berbeda dengan data sekunder sebelumnya, pada daerah tanggul bendungan hanya dipakai satu lintasan yaitu data sekunder yang dipakai oleh Sheffer (2007). Data tersebut adalah lintasan survei B-B' di British Columbia, Kanada. Profil anomali pada data sekunder 3 ini didijitasi sebanyak 25 titik dengan interval $10 \mathrm{~m}$.Selanjutnya, dilakukan proses inversi dengan menggunakan pendekatan untuk ketiga bentuk sumber anomali (sphere, horizontal cylinder, dan vertical cylinder) dan perhitungan nilai RMS error. Nilai setiap parameter untuk anomali ini didapatkan dari hasil inversinya (Tabel 4).

Tabel 4. Nilai parameter dari anomali di daerah tanggul bendungan di British Columbia, Kanada

\begin{tabular}{|c|c|c|c|}
\hline $\begin{array}{c}\text { Kedalaman } \\
\text { (z) }\end{array}$ & $\begin{array}{c}\text { Shape } \\
\text { factor } \\
\text { (q) }\end{array}$ & $\begin{array}{c}\text { Sudut } \\
\text { polarisasi } \\
(\boldsymbol{\theta})\end{array}$ & $\begin{array}{c}\text { Momen } \\
\text { dipol listrik } \\
\text { (k) }\end{array}$ \\
\hline $49.73 \mathrm{~m}$ & 0.48 & $18.52^{\circ}$ & 22.03 \\
\hline
\end{tabular}

Selain itu, hasil dari proses inversinya menunjukkan bahwa model vertical cylinder yang paling mendekati kondisi sekunder (sebenarnya) karena memiliki nilai RMS error terkecil (Tabel 5).

Tabel 5. Perbandingan RMS error untuk tiga bentuk anomali pada data sekunder 3

\begin{tabular}{|c|c|}
\hline Shape body & RMS error \\
\hline Sphere & 93.82 \\
\hline Horizontal cylinder & 42.86 \\
\hline Vertical cylinder & 10.97 \\
\hline
\end{tabular}

Hasil tersebut sesuai karena anomali di daerah tanggul bendungan di British Columbia merupakan rembesan air yang berhubungan dengan kedalaman muka air tanah (hydraulic head), aliran air tanah di dalam struktur lapisan serta karena data sekunder ini hal yang menyebabkan anomalinya berupa potensial streaming (Sheffer, 2007).

\section{PENUTUP}

Kesimpulan

Berdasarkan hasil penelitian ini, dapat disimpulkan beberapa hal mengenai pemodelan numerik ini. 
1. RMS error hasil pemodelan pada data sintetik untuk ketiga bentuk sumber anomali adalah dibawah $10 \%$, hal ini membuktikan bahwa program yang dibuat sudah bisa diterapkan pada data sekunder.

2. Perbedaan kedalaman sebesar $27,5 \mathrm{~m}$ pada anomali Weiss disebabkan karena pada lintasan A-A' dan B-B' terdapat anomali yang berbeda, sedangkan untuk sumber anomalinya adalah sphere karena merepresentasikan mineral tembaga yang terdapat pada daerah tambang tersebut.

3. Sumber anomali pada data sekunder 3 di daerah British Columbia yang berupa vertical cylinder mengindikasikan adanya rembesan (seepage) yang terjadi pada tanggul bendungan tersebut dimana arah aliran sungainya dari Barat daya menuju Timur laut.

\section{Saran}

Berdasarkan kesimpulan penelitian, maka penulis merekomendasikan berupa saran-saran sebagai berikut.

1. Untuk mendapatkan hasil inversi yang lebih baik dan error RMS yang kecil, dapat digunakan proses iterasi untuk mendapatkan nilai shape factor baru yang akan digunakan untuk proses inversi.

2. Perlu dilakukan pemodelan numerik dengan metode yang lainnya seperti curve matching atau derivative analysis sebagai pembanding untuk hasil inversi pada perhitungan parameter anomali SP-nya.

\section{Ucapan Terima Kasih}

Penulis mengucapkan terimakasih kepada keluarga atas doa dan dukungannya serta dosen pembimbing Pak Dwa Desa Warnana atas bimbingan dan pengarahannya selama proses penelitian hingga penulisan.

\section{DAFTAR PUSTAKA}

Abdelrahman, E. M. et al.1997.A least-squares approach to shape determination from residual self-potential anomalies. Pure and Applied Geophysics, Vol. 150: 121-128.

Bhattacharya, B. B., and Roy, N.1981. A note on the use of nomogram for self-potential anomalies, Geophysical Prospecting, Vol. 29: 102-107.
El-Araby, H. M.2004. A New Method for Complete Quantitative Interpretation of Self-potential Anomalies, Vol. 55: 211-224.

Hazra, A.2010. A FORTRAN code for quantitative interpretation of self potential anomalies. 8th Biennial International Conference\& Exposition on Petroleum Geophysics.

Makhrani, "Optimalisasi Desain Parameter Sekunder Untuk Data Resistivitas Pseudo 3D", Program Studi Geofisika Jurusan Fisika FMIPA Universitas Hasanuddin, 2013

Minsley, B. J.1997. Modeling and Inversion of SelfPotential Data, B. S. Applied Physics, Purdue University.

Revil, A. dan Abderrahim J., "The Self-Potential Method: Theory and Applications in Environmental Geosciences", New York, Cambridge University Press, 2013

Sato, M., and H.M. Mooney. 1960. The Electrochemical Mechanism of Sulfide Self-Potentials, Geophysics, Vol. 25: 226-249.

Satyanarayana Murty, B.V., dan P. Haricharen. 1985. Nomogram for the complete Interpretation of spontaneous pontential profiles over sheet-like and cylindrical two-dimensional sources, Geophysics, Vol. 50: 1127-1135.

Sheffer, M. R. 2007.Forward modelling and inversion of streaming potential for the interpretation of hydraulic conditions from self-potential data, The University Of British Columbia.

Tambunan, C., "Metode Geofisika Potensial Diri (Self Potential)", <URL: http://www.pusdiklatminerba.esdm.go.id/index.php/kerjasama/item/353metode-geofisika-potensial-diri-self-potential>, September, 2015

Telford, W. M., L. P. Geldart, dan R. E. Sheriff, “Applied Geophysics", Cambridge University Press, 1990

Yüngül, S.1950. Interpretation of Spontaneous Polarization Anomalies caused by Spheroidal Ore Bodies, Geophysics, Vol. 15: 237-246. 